\title{
Decarbonization of Industrial Energy Systems: A Case Study of Printed Circuit Board manufacturing
}

\author{
Carles Ribas Tugores ${ }^{1} \quad$ Gerald Birngruber $^{2} \quad$ Jürgen Fluch $^{1} \quad$ Angelika Swatek $^{3} \quad$ Gerald Schweiger $^{2}$ \\ ${ }^{1}$ AEE INTEC, Gleisdorf, Austria \{c.ribastugores, j.fluch $\}$ @aee.at \\ ${ }^{2}$ Technical University of Graz, Graz, Austria \{birngruber, gerald. schweiger\} @tugraz. at \\ ${ }^{3}$ ENERTEC - Naftz \& Partner GmbH \& Co KG, Graz, Austria a . swatek@enertec . at
}

\begin{abstract}
Decarbonization of industry is a key challenge to achieve the Paris climate goals. Digitalization of the industry is a cornerstone of this journey. In this paper we present our modelling work towards the creation of a Digital Energy Twin of the energy supply system of a printed circuit board manufacturing by means of a classical use case, system design optimization. The simulation approach allowed us to fairly compare the improvements done in the energy supply system by evaluating those under the same operating conditions. Integration of chiller's waste heat can cover most of the low temperature grid heat demand while the additional generation of chilled water reduces the amount of water pump from and back to the river.
\end{abstract}

Keywords: Digitalization, Industry, Modelling, Efficiency, Decarbonization

\section{Introduction}

The industry sector is one of the largest energy consumers and greenhouse gas emissions contributors. The chemical sector is the biggest industrial energy consumer, accounting for $28 \%$ of total global industry final energy demand (Philibert 2017). The industrial sector must reduce its energy intensity and dependency on fossil fuels demands to achieve the commitment of the Paris agreement to hold global warming below $1.5-2^{\circ} \mathrm{C}$ (Luderer et al. 2018). A new draft of Effort Sharing Regulation specifies a $36 \%$ emission reduction for Austria by 2030 compared to 2005 for sectors not covered by the emissions trading system (European-Commission 2019). While the power sector shows significant reductions in the different future technology scenarios, the share of industrial $\mathrm{CO} 2$ emissions will increase to $44 \%$ in the $2{ }^{\circ} \mathrm{C}$ scenario, and it has not yet attracted the same level of attention as the transport and power sectors (Philibert 2017). Three-quarters of the worldwide industrial energy demand is dedicated for process heat, with $52 \%$ of that energy required in the low and medium temperature level (Luderer et al. 2018). This shows that the target of $80 \% \mathrm{CO} 2$ reduction can only be reached if the process heat demand in the low and medium temperature range is incorporated in the energy reduction strategies.

The scientific community argues that digitization offers opportunities for sustainability, such as improved resource efficiency through optimized operation (Ghobakhloo 2020). A key concept in the digitalization are CyberPhysical Systems (CPS) and Digital Twins (DT) (J. Lee, Bagheri, and Kao 2015; Tao et al. 2019). The emergence of these concepts poses new challenges for traditional modeling approaches. Among other aspects, computational systems and communication networks need to be combined with physical systems (E. A. Lee and Seshia 2017); further, co-simulation approaches are needed to couple different tools and modeling approaches (e.g., physical and machine learning) (Schweiger, Engel, et al. 2018).

In this paper, we present our ongoing modeling work towards a Digital Energy Twin (DET) in the industry by means of a real world case studies of the energy supply system of printed circuit board manufacturing plant at AT\&S. AT\&S is a world leading company in the printed circuit board industry (PCB). The goal of AT\&S is to reduce the carbon footprint and fresh water use by yearly $5 \%$ and $3 \%$ respectively (AT\&S 2021). The optimization of the energy system is not an easy task as production plants need to be regularly adapted to the customer needs. AT\&S is managing to improve the efficiency of their plants but at the same time facing difficulties evaluate the exact impact of the taken measures and potential deviation with the expected results, i.e. to achieve an "optimum". We aim to develop a Digital Energy Twin targeted to assist on the optimization of the operational control of the system. Due to the lack of a common understanding one the definition of the Digital Twin concept it is important to note that thee authors follow the definitions for Digital Model, Digital Shadow and Digital Twin given by (Kritzinger et al. 2018). In a brief way, given a physical object and its counterpart digital object, the three concepts differ on the level of data integration. In a Digital Model the data flow between physical and digital object occurs manually. On a Digital Shadow, the information flowing from the physical to the digital object is automated. Thus, a change on the physical object will be automatically communicated to the digital model. In the Digital Twin the data flowing from physical to a digital object and vice-versa are automated.

A reasonable implementation process of a Digital Twin 
starts with a Digital Model, which data flow is step by step automated. This is a resource intensive task which requires in-deep knowledge of the system as well as large amount of data. Due to the industry needs, it is clear that not only a Digital Twin (which planned use cases are rather related to the optimal operation of the system) is of interest but a Digital Model (suitable to overall control strategies and system design offline studies) as well. Thus, we intend to efficiently use the resources being use to obtain a Digital Twin by making use of its "simplest" version, i.e. the Digital Model. The presented use case, scenario evaluation, aims to evaluate the added value of the undertaken measures to improve the efficiency of the plant by means of three exemplary scenarios. The plant is based on the real system, though only a part of the whole system has been included here.

\section{Use Cases}

Figure 1 shows an overview of the three scenarios considered. A subset of the actual warm and chilled water production system at an industrial site located in Austria.

The cooling, heating, and water demand at AT\&S can be clustered into five main consumers: Two heat consumers (a high and a low temperature grid). Data of their temperature and energy requirements are available at their main heat exchangers. HT grid supply temperature varies between $80{ }^{\circ} \mathrm{C}$ and $50{ }^{\circ} \mathrm{C}$. LT grid supply temperature varies between $40{ }^{\circ} \mathrm{C}$ and $20{ }^{\circ} \mathrm{C}$. The cooling demand is divided into two consumers, a main cooling demand with supply temperatures between $10^{\circ} \mathrm{C}$ and $6.5^{\circ} \mathrm{C}$, and a cooling demand for industrial processes, production in short. The supply temperature for production should not be lower than $11^{\circ} \mathrm{C}$ (the supply temperature is set to $\left.12{ }^{\circ} \mathrm{C}\right)$. The fifth main consumer corresponds to the process water. It requires water at warm temperature level. Exact demands for the industrial process and process water are available as hourly average values.

Scenario 1 is the base case and corresponds to a former case where the use of the utilities was not optimized. The base case is depicted at Figure 1 with help of arrows with black edges. The heat demand is entirely supplied by a gas boiler. The cooling demand is solely covered by a compression chiller which waste heat is released to the ambient by a dry cooler. The cooling demand for the industrial process (production) is covered by water from a cold water storage. The mass flow leaves production with a slightly higher temperature and is send into the warm water storage. The warm water is later used to supply the process water demand (this water cannot be reused for the industrial process and is therefore treated and dumped safely). In case that the water level of the warm water storage is too high, water is pumped back into the river (warm water overflow). Water from the warm water storage is partially re-injected into the cold water storage to temperate the cold water storage (overcooling protection) and thus minimize the amount of water pumped back into the river. The amount of water in the system is refilled with fresh water to keep the cold water storage level above a minimum threshold.

Scenario 2 is a successor of scenario 1 and integrates the chillers' waste heat. The waste heat is used to partly supply the heat demand of the LT grid, see arrows with dashed edges in Figure 1, thus reducing the amount of heat needed to be supplied by the boiler plant and with it the overall gas consumption.

Scenario 3 is an extension of scenario 2. Scenario 3 aims to reduce the amount of water overflowing the warm water storage, and that needs to be pumped back into the river. Here the condenser side of the chiller is indirectly connected to the cold and warm water storage tanks by a heat exchanger. The chiller can increase the amount of chilled water produced, and this water is used to cool down fluid from the warm water storage, which is reinjected back to the cold water storage. The amount of fresh water needed is then reduced, as well as the amount of water overflowing in the warm water storage that needs to be pumped back into the river. Because the supply of warm water for the process water needs to be ensured, the generation of additional chilled water only takes place when there is enough warm water. A hysteresis block with uLow and uHigh equal to $30 \%$ and $90 \%$ of the water level ensures the warm water supply for the consumer "process water". The additional chilled water yields an increase on waste heat. The additional chilled water is only generated under suitable conditions, i.e. there is enough heat demand at the LT grid and the additional waste heat can be thus used to further cover these need.

\section{Method}

\subsection{Modeling and Simulation}

The models were implemented in the Modelica language (Fritzson and Engelson 1998). A discussion of limitations and promising approaches of the Modelica language can be found here (Schweiger, Nilsson, et al. 2020). The main reason to opt for Modelica is the compliance of most Modelica tools with the FMI standard. Notice that the developed modelica models for the energy supply system (partially here presented) as well as Python data driven models for selected production processes are later to be exported as FMUs and imported into a project partner software (KG 2021) where the Digital Twin is to be hosted. Another important aspect to decide for Modelica is the amount of already free-available libraries for energy systems and the acquaintance of the authors with those libraries. In this regard, the models are based on the Modelica IBPSA Project 1 (Wetter, Treeck, et al. 2019) and the Buildings Library (Wetter, Zuo, et al. 2014). Dymola was used to simulate Modelica models (Brück et al. 2002).

\subsection{Model description and parametrization}

A top level view of model is shown in Figure 2. The main subsystem models are here briefly described. 


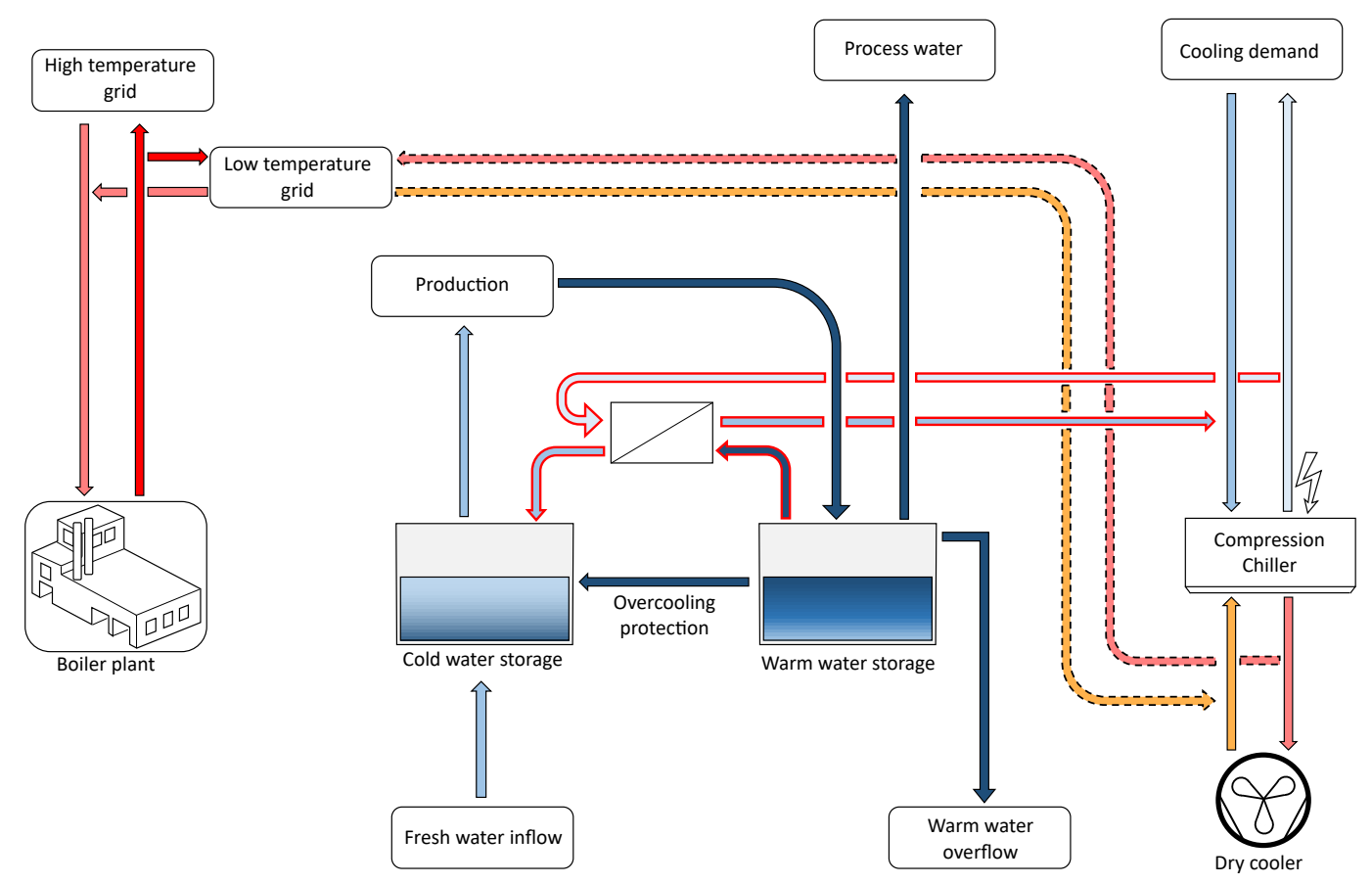

Figure 1. Schema of the industrial site. Arrows indicate mass flow rates. Arrows with dashed edges correspond to the scenario 2 and 3. Arrows with red edges correspond to scenario 3. Colours of the arrows indicate the temperature levels of the streams qualitatively.

The consumers "high temperature grid", "cooling demand", "production" and "process water" are modelled with a custom model named "GenericDemand". In this block the return temperature is prescribed. An instance of Buildings.Fluid.Interfaces.PrescribedOutlet ensures that the inflow mass flow rate is heated up (or cooled down) according to the measured data. The mass flow rate going to each consumer is regulated so that the energy demand is fulfilled. Notice that the mass flow rate leaving "process water" is flowing into a sink and not back to the water storages. The low temperature grid block contains a "GenericDemand" block inside. Here the main difference with the other demand blocks is that the mass flow rate used to cover the heat demand can come from two different sources, the boiler plant and/or the compression chiller. The waste heat coming from the compressor has priority, heat from the boiler plants is used in case there is a lack of waste heat or the waste heat supply temperature is not high enough.

The cold and warm water tanks are modelled using two instances of Modelica.Fluid.Vessels.OpenTank. These are parametrized based on constructive details of the real tanks. Total cross area and height are respected. Heat losses are not considered.

The "storage cooling HX" is modelled with a heat exchanger model with constant effectiveness, $\varepsilon=0.8$. The mass flow rate on the chiller side is determined by the overall control as explained in section 2. The mass flow rate in the storage side is regulated so that the outflow temperature, i.e. mass flow rate flowing into the cold water, reaches a temperature of $13{ }^{\circ} \mathrm{C}$.
The overcooling protection block contains mainly a pump moves fluid from the warm water storage to the cold one when the temperature of the cold storage drops below its minimum allowed of $1{ }^{\circ} \mathrm{C}$.

The cold and water storage logic controls is based on models from the StateGraph library. It monitors the temperature and water levels of the warm and cold storage and includes the necessary logic to "activate/deactivate" different subsystems, e.g. the overcooling protection block, fresh water supply and overflow (to keep water level of the storages within certain limits) or the chiller (additional generation of chilled water used in scenario 3 ).

The boiler plant is modelled using an instance of Buildings.Fluid.Boilers.BoilerPolynomial. The nominal power of the boiler is set to $3.5 \mathrm{MW}$. The efficiency is defined by a polynomial which coefficients are obtained by curve fitting to measured data, see Figure 3.

The chiller installed at AT\&S is TCHVBZ 31630 BT from the manufacturer Rhoss. It is modelled using the Buildings.Fluid.HeatPumps.ScrollWaterToWater model. The necessary information to parametrize the model cannot be directly obtained from a data sheet. For that purpose the buildings library supplies Python code. It mainly consists of the same implementation of the heat pump and refrigerant properties available in Modelica as well as a script. Given data on specific operating conditions (each defined by inflow temperature, mass flow rate and heat flow rate at the evaporator and condenser as well as the electrical consumption of the compressor) the script simulates the Python chiller model iteratively for all operating points adjusting the parameters 


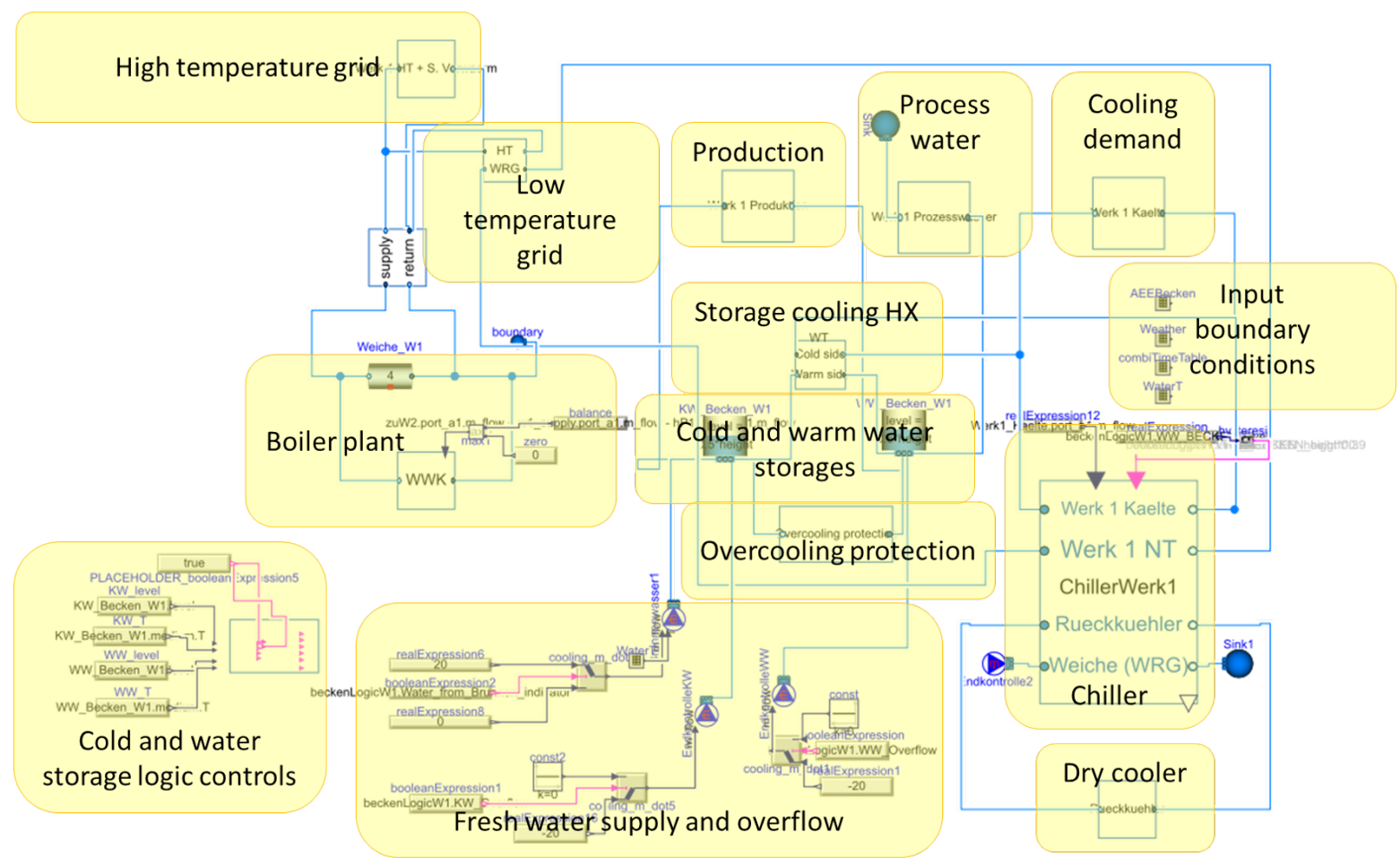

Figure 2. Top level view of the Modelica model.

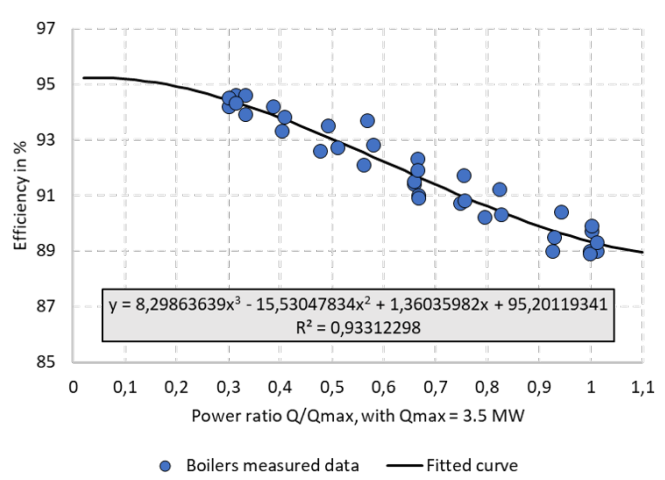

Figure 3. Measured boiler efficiency and fitted curved.

until an "optimum" parametrization that minimize the error between model output and given operational conditions is found. The available version of the buildings' heat pump model is ready to be used with the refrigerant R401. The chiller TCHVBZ 31630 BT uses R134a as a refrigerant. Following the same approach used in Buildings.Media.Refrigerants.R410A, an implementation for R134a based on data from (Chemour 2021) is added in Modelica and Python. In regard of the parametrization, up to 28 different operating conditions were supplied by the manufacturer for this chiller. The information is summarized in the Appendix. The parametrization process is sensitive to the data used. In some case the Python script does not manage to find a proper parametrization. This is the case when all 28 operating points or data related to very different load conditions (e.g. full- $100 \%$ and low
Table 1. List of operating points per dataset. Operating points number refer to points listed in Table A.2.

\begin{tabular}{|c|c|}
\hline Dataset & ${\text { Operating points } \mathrm{n}^{\circ}}^{\circ}$ \\
\hline $\mathrm{A}$ & $4,8,12,16,20,24,28$ \\
\hline $\mathrm{B}$ & $3,7,11,15,19,23,27$ \\
\hline $\mathrm{C}$ & $3,4,7,8,11,12,15,16,19,20,23,24,27,28$ \\
\hline $\mathrm{D}$ & $2,6,10,14,18,22,26$, \\
\hline $\mathrm{E}$ & $2,3,6,7,10,11,14,15,18,19,22,23,26,27$ \\
\hline $\mathrm{F}$ & $1,5,9,13,17,21,25$ \\
\hline $\mathrm{G}$ & All points except $4,8,12,16,20,24,28$ \\
\hline $\mathrm{H}$ & $1,2,5,6,9,10,13,14,17,18,21,22,25,26$ \\
\hline
\end{tabular}

load-25\% operation) is used. A list of datasets that were used as input for the Python script that successfully outputted a "optimum" parameter set are listed in Table 1. 
After the script is run for the datasets A to $\mathrm{H}$, the obtained parameter sets are cross checked with all 28 operating points. The heat pump is setup in a way that the inflow temperatures at evaporator and condenser side as well as the mass flow rate trough the evaporator correspond to the measured data. The signal compressor frequency $y$ is adjusted so that the outflow temperature at the evaporator corresponds with the measured data, thus the chilled water generated should agree with the measured data. The mass flow rate at the condenser does not correspond to the measured one, it is adjusted so that the outflow temperature matches the measured data.

The results show how for the parameter sets obtained with $\mathrm{A}, \mathrm{B}, \mathrm{C}, \mathrm{E}$ and $\mathrm{G}$ the chiller cannot deliver the requested heat flow rate at the evaporator, see Figure 4. In the case of the parameter sets obtained with $\mathrm{D}, \mathrm{F}$ and $\mathrm{H}$, the chiller is able to deliver the requested chilled water for most of the operating points.

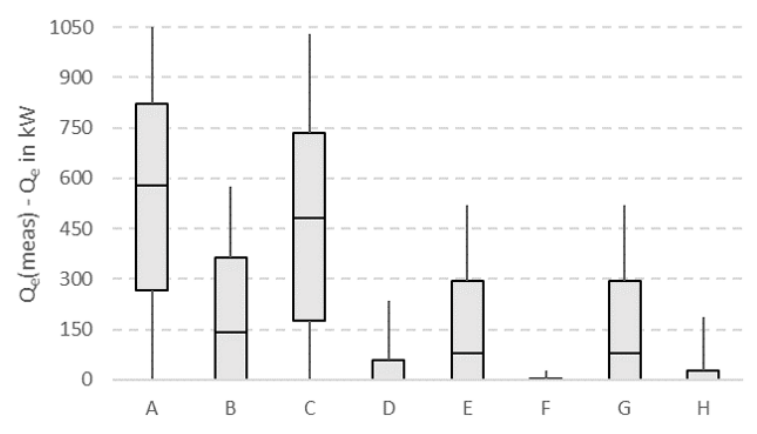

Figure 4. Deviation of heat flow rate at evaporator $Q_{e}$ : Measured - model output.

From the three remaining parametrization sets, D shows very good results for most of operating points but not for full load operation. $\mathrm{F}$ and $\mathrm{H}$ shows better results for full load operation but higher deviations for most of the other operating points, see Figure 5. It is clear that if the datasets used do not include operating points on full load, the obtained parameter set or rather the parametrized model will not be able to predict correctly the real system under such conditions. However, the chiller does not operate at full load. Because it is by now not planned to operate the chiller in very different conditions than it is being operated, e.g. full load, the use of parametrization "D" suits better our needs. In regard of the electrical consumption, result obtained based on dataset $\mathrm{D}$ shows an average deviation of $+7 \%$ with a minimum (overprediction) and maximum (underprediction) deviation of $-7 \%$ (point $\mathrm{n}^{\circ} 16$ ) and $23 \%$ (high load operation) respectively.

\subsection{Model validation}

The energy system is been monitored in detail and most of the data are recorded. However, there is in some cases not enough data (due to missing measurement equipment or problems in the measuring device) to perform an energy or mass balance of some subsystems, this is the case for

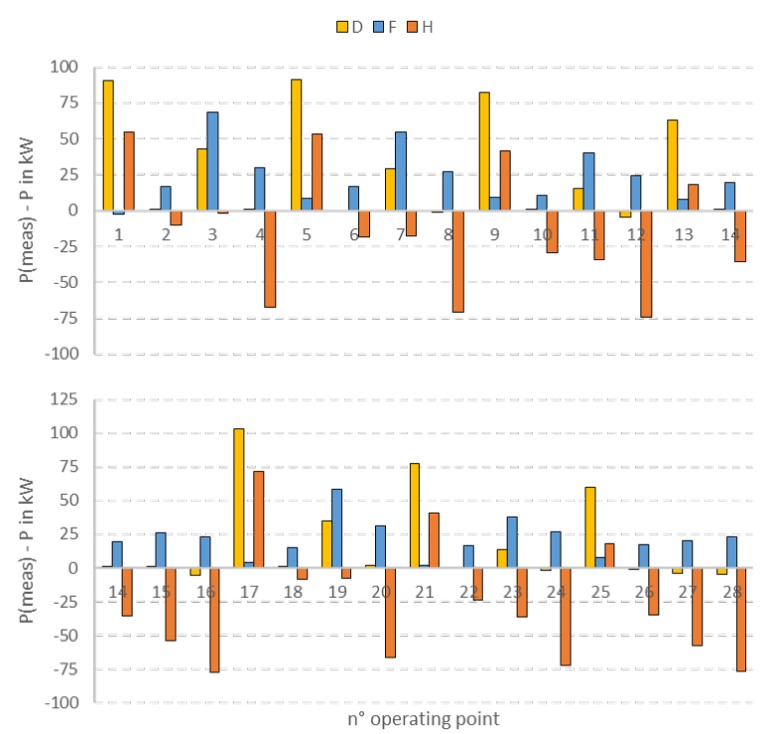

Figure 5. Deviation of electrical consumption $P$ : Measured model output.

e.g. the boiler plant or the cold and warm water storage. In this regard, the validation work have been focused on the chiller. The same model used for the parametrization check is here used, the only difference is that measured data are used instead of single operating points. A time period of six days, from 7th until 13th of Februar 2021, is here presented.

The amount of chilled water as well as operating temperatures are the same between model and measured data. An overview of the temperature operating range is shown in Figure 6. The chiller is working at low load $(115 \mathrm{~kW}$ of cooling capacity in average with a maximum and minimum of $182 \mathrm{~kW}$ and $71 \mathrm{~kW}$ respectively) and supplying chilled water at low temperature $\approx 7{ }^{\circ} \mathrm{C}$.

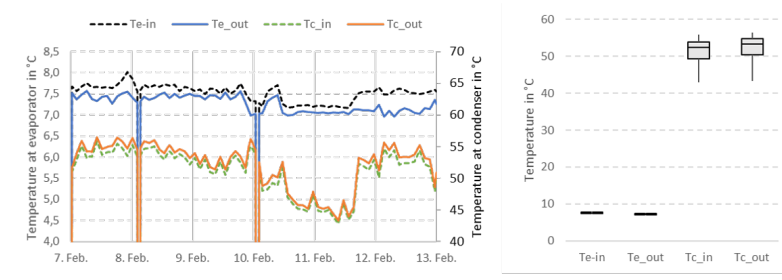

Figure 6. Operating temperatures for chiller during validation time period.

The deviations between measured data and model results can be observed in the electrical consumption and heat flow rate at the condenser and thus, EER. The differences are shown in Figures 7 to 9.

The results show how the model predicts a slightly higher but similar electrical consumption than the real system, being the average for the model and measured $62.8 \mathrm{~kW}$ and $60.9 \mathrm{~kW}$ respectively. These good agreement in the power consumption yields a similar EER, 1.88 for the model and 1.93 measured. Here is to point out that 

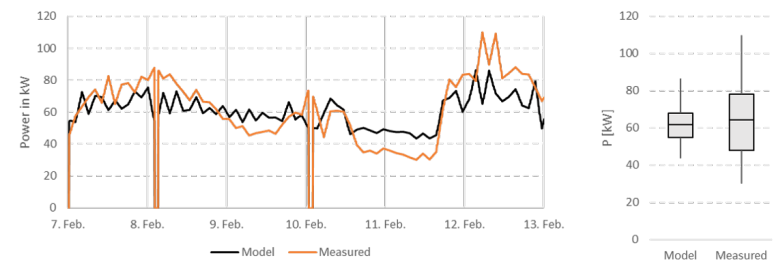

Figure 7. Electrical consumption $P$ (measured and model output).

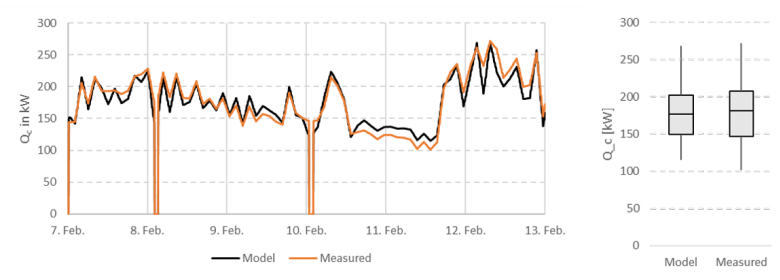

Figure 8. Heat flow rate at condenser $Q_{c}$ (measured and model output).

the operating conditions are similar to the operating point number 20 (see Table A.2). Operating conditions under which the model oversestimates the power consumption by less than $2 \%$.

\subsection{Scenario evaluation}

The evaluation of the scenarios is due to limited measured data done for a period of time equal to 150 days, roughly five months.

Notice that since the exact costs of water overflow, fresh water inflow, and dry coolers cannot yet be in detail evaluated (details of the system missing), thus the added value of the scenarios is limited to the main production units (boiler and chiller) as well as the amount of water pumped. The following main KPIs are considered:

- Heat supplied to the LT grid by boiler plant in MWh,

- Waste heat recovery from chiller in MWh,

- Share of heat demand at LT grid supplied by waste heat in \%,

- Chiller electricity consumption in MWh,

- Fresh water into cold water storage in $\mathrm{m}^{3}$,

- Overflowed water at warm water storage $\mathrm{m}^{3}$.

\section{Results and Discussion}

Because the HT grid is merely supplied by the boiler plant, this is not of interest for the scenario evaluation and discussion and thus, not included here. In regard of the heat supply, once the waste heat of the chiller is integrated into the LT grid, the amount of heat been supplied by the boiler plant can be reduced from 1,053 MWh down to $104 \mathrm{MWh}$. The rest of the heat demand $(90.1 \%$ of the overall LT grid

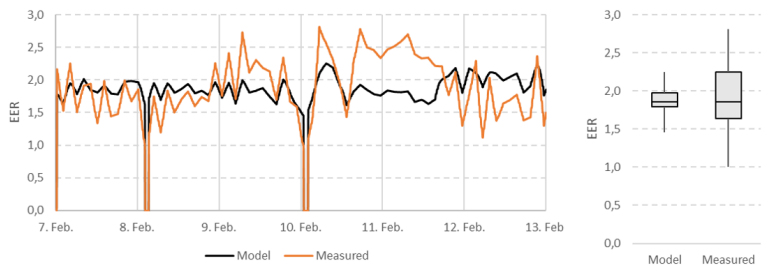

Figure 9. Energy efficiency ratio (measured and model output).

heat demand) is covered by waste heat from the chillers, see Figure 10.

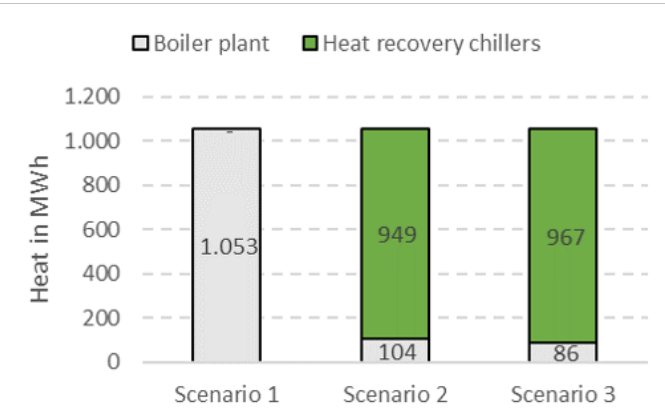

Figure 10. Share of heat supplied to cover the LT grid heat demand.

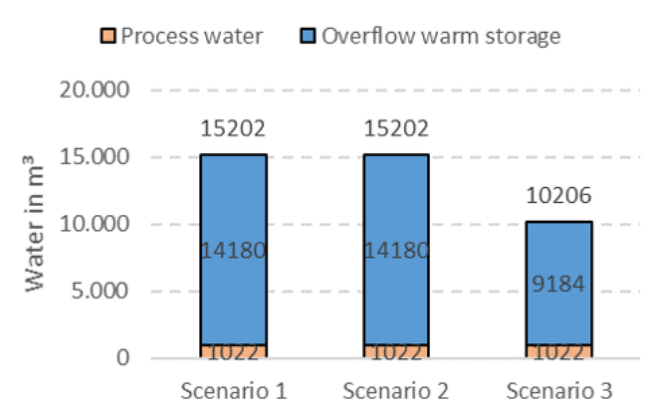

Figure 11. Total amount of fresh water needed divided into process water and overflow.

The operation conditions of the chiller in scenario 1 and 2 are almost the same. The same amount of chilled water $(1,543 \mathrm{MWh})$ is produced. There is a slight difference on the temperatures at the condenser side when heat is been supplied to the low temperature grid that yield a slight variation on the electricity consumption, being in scenario $2-1.4 \%$ lower than scenario 1 .

The amount of fresh water needed remains the same, $15,202 \mathrm{~m}^{3}$. Most of it is pumped back into the river $\left(14,180 \mathrm{~m}^{3}\right)$, and the rest $\left(1,022 \mathrm{~m}^{3}\right)$ is used as process water, see Figure 11. The amount of water used to keep the temperature at the cold water storage above its minimum allowed temperature of $11{ }^{\circ} \mathrm{C}$ decreases with time due to an increase on the river temperature, see Figure 12.

The fact that not all the LT grid heat demand is covered by the waste heat of the chiller and the high amount of wa- 


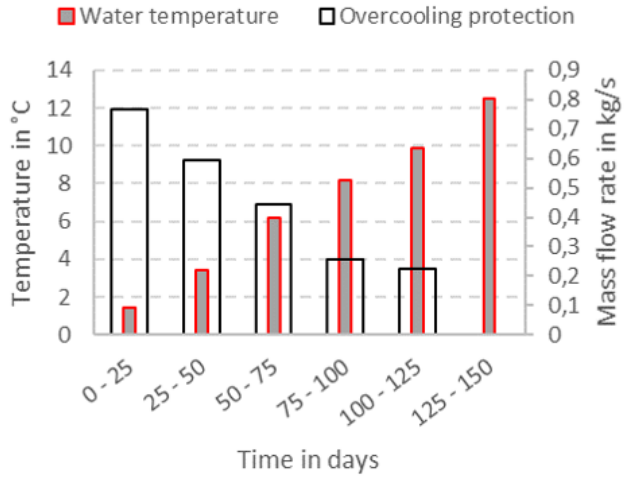

Figure 12. 25 days averaged values of river temperature and mass flow rate from warm to cold water storage (overcooling protection).

ter been pumped back into the river $\left(14,180 \mathrm{~m}^{3}\right)$ motivates scenario 3.

The amount of additional chilled water generated in scenario 3 (112 MWh) is relatively low compared to the overall amount of chilled water supplied to the main cooling demand (1,543 MWh). It represents only $6.8 \%$ of the overall chilled water in MWh. The change in the electricity consumption and amount of waste heat are low, both slightly increasing. As a result, the share of the LT grid heat demand supplied by waste heat is increased from $90.1 \%$ in scenario 2 up to $91.8 \%$. The electricity consumption is $390 \mathrm{MWh}(6.6 \%$ higher than scenario 2).

The main added value of scenario 3 is related to the reduction of the amount of fresh water that is pumped into the cold water storage, which is specifically reduced by $32.9 \%$ compared to scenario 1 and 2, i.e., down to $10206 \mathrm{~m}^{3}$. Furthermore, the amount of water that have to be pumped back into the river, is also reduced by $35.2 \%$ respect to the scenario 1 and 2 down to $9184 \mathrm{~m}^{3}$.

\section{Conclusion}

Though the digitalization is often directed towards the creation of Digital Twins, the industry still lacks of groundwork, e.g., Digital Models. The amount of work need to create a Digital Model of a factory is high. Furthermore, it needs of expertise, in regard of the modeling task itself as well as of the knowledge of the system. The much-desired digitalization needs a positive balance between added value and effort. Thus, the use of the models needs to be maximized by using it e.g. to assist on regular tasks such as comparative analysis of potential improvements of the system and evaluation of measures taken (as here presented). In this regard, the improvements done in the energy supply system could be fairly compared with the former system. The results show the benefits of the chiller's waste heat integration as well as the generation of additional chilled water. In regard of the model, highlight that the heat pump model can predict accurately the power consumption of the real chiller, though the results are very sensitive to the data used on the parametrization and the choose of a proper parametrization depends on the real operation conditions and planned studies.

\section{Acknowledgements}

The research leading to these results has received funding from the Austrian Climate and Energy Fund Programme Energy Research (e!MISSION) under FFG project no. 873599 .
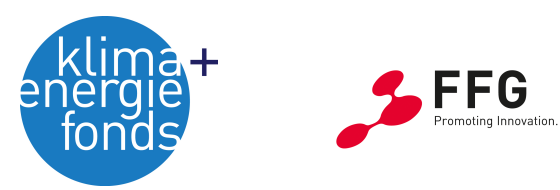

\section{References}

AT\&S (2021). AT\&S Nachhaltigkeit. https : / / ats . net / de / unternehmen/corporate-social-responsibility/.

Brück, Dag et al. (2002). "Dymola for multi-engineering modeling and simulation". In: 2nd International Modelica Conference.

Chemour (2021). Freon ${ }^{\mathrm{TM}} 134 a(R-134 a)$. https://www. freon. de/products/refrigerants/r134a. Chemour.

European-Commission (2019). Assessment of the draft National Energy and Climate Plan of Austria. Tech. rep. EuropeanCommission.

Fritzson, Peter and Vadim Engelson (1998). "Modelica-A Unified Object-Oriented Language for System Modeling and Simulation". In: European Conference on Object-Oriented Programming. Springer, pp. 67-90.

Ghobakhloo, Morteza (2020). "Industry 4.0, digitization, and opportunities for sustainability". In: Journal of Cleaner Production 252, p. 119869. ISSN: 0959-6526. DOI: https://doi. org/10.1016/j.jclepro.2019.119869.

KG, Eberle Automatische Systeme GmbH \& Co (2021). Virtual 3D Systems. https://www.v3s.at/de/.

Kritzinger, Werner et al. (2018). "Digital twin in manufacturing: A categorical literature review and classification". In: IFACPapersOnLine 51.11. 16th IFAC Symposium on Information Control Problems in Manufacturing INCOM 2018, pp. 10161022. ISSN: 2405-8963. DOI: https://doi.org/10.1016/j.ifacol. 2018.08.474.

Lee, Edward A. and Sanjit A. Seshia (2017). Introduction to Embedded Systems: A Cyber-Physical Systems Approach. Mit Press. ISBN: 978-0-262-53381-2.

Lee, Jay, Behrad Bagheri, and Hung-An Kao (2015). "A CyberPhysical Systems architecture for Industry 4.0-based manufacturing systems". In: Manufacturing Letters 3, pp. 18-23. ISSN: 2213-8463. DOI: https://doi.org/10.1016/j.mfglet.2014. 12.001 .

Luderer, Gunnar et al. (2018). "Residual fossil CO 2 emissions in 1.5-2 C pathways". In: Nature Climate Change 8.7, pp. 626-633.

Philibert, Cédric (2017). "Renewable Energy for Industry: From Green Energy to Green Materials and Fuels". In: Paris: International Energy Agency.

Schweiger, Gerald, Georg Engel, et al. (2018). "Co-simulationan empirical survey: applications, recent developments and future challenges". In: MATHMOD 2018 Extended Abstract Volume, pp. 125-126. 
Schweiger, Gerald, Henrik Nilsson, et al. (2020). "Modeling and simulation of large-scale systems: A systematic comparison of modeling paradigms". In: Applied Mathematics and Computation 365 , p. 124713.

Tao, Fei et al. (2019). "Digital Twins and Cyber-Physical Systems toward Smart Manufacturing and Industry 4.0: Correlation and Comparison". In: Engineering 5.4, pp. 653-661. ISSN: 2095-8099. DOI: https://doi.org/10.1016/j.eng. 2019. 01.014.

Wetter, Michael, Christoph van Treeck, et al. (2019). "IBPSA Project 1: BIM/GIS and Modelica framework for building and community energy system design and operation-ongoing developments, lessons learned and challenges". In: IOP Conference Series: Earth and Environmental Science. Vol. 323. IOP Publishing, p. 012114.

Wetter, Michael, Wangda Zuo, et al. (2014). "Modelica Buildings library". In: Journal of Building Performance Simulation 7.4, pp. 253-270. DOI: 10.1080/19401493.2013.765506. 


\section{A Appendix}

Table A.2. Detailed list of operating points for TCHVBZ 31630 BT

\begin{tabular}{|c|c|c|c|c|c|}
\hline $\mathrm{n}^{\circ}$ & $T_{c-i n}\left[{ }^{\circ} \mathrm{C}\right]$ & $T_{e-i n}\left[{ }^{\circ} \mathrm{C}\right]$ & $Q_{e}[\mathrm{~kW}]$ & $Q_{c}[\mathrm{~kW}]$ & $\mathrm{P}[\mathrm{kW}]$ \\
\hline \hline 1 & 40 & 7 & 1,150 & 1,568 & 418 \\
\hline 2 & 42 & 7 & 959 & 1,295 & 336 \\
\hline 3 & 43 & 7 & 684 & 953 & 269 \\
\hline 4 & 46 & 7 & 321 & 434 & 113 \\
\hline 5 & 35 & 7 & 1,240 & 1,633 & 392 \\
\hline 6 & 36 & 7 & 1,023 & 1,331 & 308 \\
\hline 7 & 38 & 7 & 739 & 981 & 241 \\
\hline 8 & 41 & 7 & 343 & 446 & 103 \\
\hline 9 & 29 & 7 & 1,346 & 1,705 & 359 \\
\hline 10 & 31 & 7 & 1,109 & 1,393 & 284 \\
\hline 11 & 33 & 7 & 805 & 1,021 & 217 \\
\hline 12 & 36 & 7 & 371 & 467 & 95 \\
\hline 13 & 19 & 7 & 1,467 & 1,766 & 299 \\
\hline 14 & 21 & 7 & 1,218 & 1,460 & 242 \\
\hline 15 & 23 & 7 & 904 & 1,079 & 175 \\
\hline 16 & 26 & 7 & 408 & 489 & 81 \\
\hline 17 & 39 & 10 & 1,294 & 1,736 & 442 \\
\hline 18 & 41 & 10 & 1,066 & 1,409 & 343 \\
\hline 19 & 43 & 10 & 767 & 1,038 & 270 \\
\hline 20 & 46 & 10 & 357 & 472 & 115 \\
\hline 21 & 29 & 10 & 1,452 & 1,817 & 366 \\
\hline 22 & 31 & 10 & 1,202 & 1,492 & 290 \\
\hline 23 & 33 & 10 & 883 & 1,099 & 217 \\
\hline 24 & 36 & 10 & 403 & 500 & 97 \\
\hline 25 & 19 & 10 & 1,593 & 1,899 & 306 \\
\hline 26 & 20 & 10 & 1,343 & 1,591 & 248 \\
\hline 27 & 22 & 10 & 1,002 & 1,178 & 176 \\
\hline 28 & 25 & 10 & 450 & 533 & 83 \\
\hline & & & & & \\
\hline
\end{tabular}

